\title{
A BRINCADEIRA DAS CRIANÇAS NA FORMAÇÃO DE PROFESSORAS DE EDUCAÇÃO INFANTIL ${ }^{1}$
}

Andréa Simões Rivero ${ }^{2}$

\section{As crianças e suas infâncias na educação infantil}

As reflexões em torno das crianças e suas infâncias, ocorridas nos últimos anos na área de educação infantil ${ }^{3}$, vêm indicando que é imprescindível buscar a voz das crianças pequenas sobre suas experiências no contexto das instituições de educação infantil.

Mas as vozes das crianças pequenas, que se constituem em diversos modos de expressão, ainda são pouco conhecidas, valorizadas e legitimadas.

Historicamente temos dirigido nosso olhar e nossa escuta mais para as falas das crianças, para sua linguagem oral. É interessante observar que dessa forma continuamos privilegiando aquelas manifestações das crianças que se assemelham ao modo como os adultos se expressam, desconsiderando suas outras linguagens. Compreendê-las na sua singularidade, nas suas diversidades, nos seus jeitos de ser, exige que nós encontremos novas formas de aproximação aos universos infantis presentes em nossas instituições, considerando que esses universos são compostos por todas as dimensões do humano, por todas as formas de produção e manifestações culturais. [...] uma aproximação aos universos infantis buscando estranhar o que parece familiar, pois todos os dias vemos as crianças brincando, chorando, dormindo, comendo, desenhando... e isto não tem ressonância, não tem eco na organização do trabalho pedagógico. Conseqüentemente, estes e tantos outros dos seus modos de viver não têm sido considerados pontos relevantes para refletirmos sobre a organização do cotidiano

\footnotetext{
${ }^{1}$ Refiro-me aos sujeitos no feminino, em virtude de os grupos com os quais tenho trabalhado serem constituídos em sua maioria absoluta por mulheres.

2 Professora do Centro Universitário Municipal de São José (USJ). Doutoranda do Programa de PósGraduação em Educação da Universidade Federal de Santa Catarina - PPGE/UFSC. E-mail: deiarivero@gmail.com.

${ }^{3}$ A contribuição de outros campos científicos, sobretudo da sociologia e da antropologia, têm sido fundamentais para a ampliação de nossa compreensão sobre as crianças e suas infâncias.
} 
das crianças e o viver da infância nas instituições de educação infantil. (BATISTA, CERISARA, OLIVEIRA E RIVERO, 2004, p. 4)

A proposta de uma aproximação às crianças pode ser entendida, segundo afirmam as autoras, como um encontro entre os adultos e a alteridade da infância ${ }^{4}$, levando-nos a redirecionar o olhar, romper com as perspectivas pelas quais culturalmente aprendeuse a enxergá-las: seres incompletos, sem fala, assexuados, inocentes, um vir a ser....

De acordo com Coutinho (2002), conceber as crianças como seres diferentes dos adultos possibilita planejar sua educação de forma diferenciada, com espaços e tempos que oportunizem a elas protagonizar essa experiência na sua heterogeneidade.

Entretanto, as vivências simultâneas e plurais constitutivas das crianças pequenas, entre as quais estão as suas brincadeiras, ainda estão por ser valorizadas e observadas mais atentamente nas instituições de educação infantil. Machado (1996) nos auxilia a analisar as possíveis razões dessa situação: segundo ela, o termo pedagógico é, na maioria das vezes, utilizado em creches e pré-escolas para distinguir atividades nobres das menos nobres. Atividades que conferem maior status e cientificidade são chamadas de pedagógicas - os jogos dirigidos, as colagens e desenhos coletivos ou, mais especialmente, atividades voltadas ao ensino da escrita e da leitura aquelas que, no entender dos adultos, ensinam algo às crianças. Todavia, a autora esclarece que não é a atividade em si que ensina, mas é a possibilidade de interagir, de trocar experiências e de partilhar significados que possibilita às crianças o acesso a novos conhecimentos.

Segundo Batista, Cerisara, Oliveira e Rivero (2004, p. 7), a construção desse outro olhar exige que abandonemos o modelo histórico-social de educação em que as manifestações culturais das crianças são consideradas na maioria das vezes como pouco educativas, não-formadoras de um adulto competente. Entre essas manifestações, as autoras salientam a brincadeira:

O brincar, e em especial, as brincadeiras livres, parecem ser vistas como uma atividade menos nobre na creche e na pré-escola, porque não apresentam um produto e, conseqüentemente, não têm o caráter "pedagógico". Mais ainda, na brincadeira, o adulto se vê destituído do

\footnotetext{
${ }^{4}$ Segundo Larrosa (1997:70), a alteridade da infância deve ser compreendida como algo radical, ou seja: “[...] nada mais nada menos do que sua absoluta heterogeneidade no que diz respeito a nós e a nosso mundo, sua absoluta diferença. E se a presença enigmática da infância é a presença de algo radical e irredutivelmente outro, dever-se-á pensá-la a partir do que sempre nos escapa: à medida que inquieta o que sabemos (e a soberba da nossa vontade de saber), à medida que suspende o que sabemos (e a arrogância de nossa vontade de poder) e à medida que coloca em questionamento os lugares que construímos para ela."
} 
papel de professor, de alguém que ensina, e o aluno não é mais aquele que aprende. Na brincadeira, o adulto não tem o controle do conteúdo e das aprendizagens. Não é ele quem decide as regras, o enredo, o cenário, o tempo, o produto. Portanto, a brincadeira, para ele, não tem validade como "atividade pedagógica".

Como professora de cursos de formação de professores de educação infantil, tenho buscado a construção de uma prática pedagógica que dirija às crianças um outro olhar , capaz de perceber seus diferentes modos de viver e expressar-se. Um dos focos desse trabalho tem sido a brincadeira e suas implicações na prática pedagógica.

\section{Uma reflexão sobre as brincadeiras das crianças na formação de professoras de educação infantil}

Ao propor o estudo da brincadeira em cursos de formação de professoras de educação infantil, tenho procurado ouvir as alunas com a intenção de conhecer suas concepções acerca desse tema e trabalhar a partir de seus pontos de vista. Os depoimentos da grande maioria das alunas têm revelado indícios de uma visão muito presente ao longo dos séculos, a partir da qual a brincadeira é concebida predominantemente como atividade inata das crianças, manifestação natural, fonte de prazer, meio de ensino-aprendizagem. Quando questionadas sobre os modos como a brincadeira deve ser proposta às crianças, percebem-se opiniões que remetem à idéia de recreação e de jogo didático.

A presença dessas concepções entre alunas que iniciam sua formação na área de educação infantil, muitas das quais já atuam como professoras de crianças pequenas, tem me levado a propor-lhes a problematização dos significados atribuídos às brincadeiras das crianças em uma perspectiva histórica, a partir do reconhecimento de que essas não são visões naturais.

Entendo que essa discussão se faz necessária em virtude das possíveis relações entre o modo como concebemos a brincadeira e os modos como a possibilitamos no cotidiano da educação infantil.

\subsection{As relações entre jogo e educação}


A obra de Gilles Brougère (1998), "Jogo e Educação", auxilia-nos a refletir sobre as relações entre jogo e educação em uma perspectiva histórica. $\mathrm{O}$ autor alerta para o risco de continuar a repetir o discurso que conduz à idéia de que o jogo é uma panacéia, discurso "[...] ligado ao encanto romântico de uma natureza que o teria oferecido à criança para que aprendesse espontaneamente”. Para ultrapassar esse patamar, afirma que precisamos ampliar nosso conhecimento sobre o jogo, sobre suas possibilidades, mas também sobre suas limitações. Trata-se, segundo o autor, da necessidade de conhecer a lógica dos discursos sobre o jogo para construir um discurso racional sobre o seu possível uso na educação das crianças e evitar um discurso ingênuo sobre ele.

Durante o século XIX, com o pensamento romântico, surge um pensamento que realmente associa jogo e educação. Uma nova concepção de criança e de natureza possibilita a descoberta de valores educativos no jogo ou na brincadeira da criança, o que contribui, segundo Brougère (1998, p.53), para que essa atividade passe a ser concebida como uma atividade séria da criança e a ser considerada como meio possível de educação.

Mas muito antes da revolução romântica já podem ser encontradas algumas concepções que estabelecem relações entre jogo e educação. A idéia de jogo associada à de relaxamento e recreação é encontrada em Aristóteles (385 a.C), em Plutarco (I), em Tomás de Aquino (XIII) e em Sêneca (XVII). A perspectiva desses filósofos contribui para a construção da idéia de que o jogo é o momento do tempo escolar que não é consagrado à educação, mas ao repouso necessário antes da retomada do trabalho. Essa perspectiva implica uma oposição entre recreação e ensino ou entre jogo e trabalho, na qual se configura que " o jogo não pode ter um fim em si mesmo, não pode ter valor próprio, ele vale em função de sua submissão ao trabalho, aos estudos”. Essa visão, de acordo com Brougère (1998, p. 54), evidencia-se hoje na oposição entre o tempo da aula e o do jogo, e eu acrescentaria, aplicando-a à situação encontrada na educação infantil entre o tempo das atividades consideradas pedagógicas e o tempo da brincadeira livre. Segundo essa perspectiva, as crianças devem ser livres para determinar o conteúdo da recreação, desvalorizado por sua futilidade fundamental.

Em estudos de Quintiliano (I), Erasmo (XVI), Basedow (XVIII) já se encontra a idéia de jogo; veja-se a afirmação feita em 1529 por Erasmo (apud BROUGÈRE, 1998, p. 55) : 
Essa maneira doce de transmitir as informações às crianças fará com que se assemelhem a um jogo e não a um trabalho, pois, nessa idade, é necessário enganá-la com chamarizes sedutores, já que não podem compreender todo o fruto, todo o prazer que os estudos devem lhes proporcionar no futuro.

O jogo seria um meio ou um suporte para seduzir a criança. Do jogo dever-se-ia utilizar sua motivação - o interesse que provoca na criança. É a idéia do lúdico como exercício didático ou como artifício pedagógico que traz em seu bojo a visão de que o trabalho deve se assemelhar ao jogo, porém não se trata de jogo, só guarda sua aparência. Portanto, esclarece Brougère (1998, p.55), nessa perspectiva o jogo em si mesmo "não possui um valor educativo, mas o estudo deve assumir o aspecto do jogo para interessar a criança, mantendo sua finalidade, suas virtudes educativas, que não são questionadas."

Contudo, há algo novo nessas idéias - a identificação da estreita relação entre infância e jogo, ou ainda o interesse pela criança tal como ela é, mesmo que se trate de tirar proveito disso para enganá-la.

[...] em Erasmo vemos muita desconfiança na natureza infantil e Basedow ainda não aplica totalmente a mensagem naturalista contida no texto de Rousseau. O jogo é justificado essencialmente por seus atrativos. No entanto, e trata-se de uma abertura através da qual surgirá uma nova visão de jogo, o educador tenta se apoiar, embora com desconfiança, em uma especificidade infantil considerada positiva. A sistematização da utilização do jogo encontrada em Basedow, sua leitura de Rousseau, podem permitir que se veja aí um momento de transição entre o puro artifício e a concepção romântica (BROUGÉRE, 1998, p. 57).

As visões de jogo como recreação e artificio didático seriam, portanto, as duas grandes direções que orientaram a relação jogo e educação ao longo dos séculos. Mas por detrás dessas concepções, segundo o autor, está uma representação da criança que impossibilita a valorização de suas atividades espontâneas. E a função atribuída ao jogo depende das representações que se tem de criança.

A visão negativa da criança, oriunda do pensamento cristão (pecado original), sustenta-se no pressuposto de que a natureza, marcada pelo mal, não pode inspirar confiança em suas ações espontâneas. Essa tradição cristã vai ao encontro de perspectivas como a de Descartes, que salienta a fragilidade da razão na criança e de que não é possível confiar nas produções espontâneas de tal ser. A criança é percebida por como um modelo ainda imperfeito do ser que constituirá o adulto, portanto, um ser 
em falta. Essa visão, definida pelo autor como uma concepção pré-romântica de criança, evidencia-se especialmente entre os séculos XVI e XVIII.

Nesse período duas visões antagônicas são identificadas. Numa a criança é concebida como um ser mau, com uma natureza voltada ao prazer imediato, aos instintos e à desordem e desprovido de razão, portanto, incapaz, e noutra como um ser que, em virtude de sua fragilidade/dependência, é concebido como um pequeno adulto, capaz de provocar compaixão.

Porém da era cristã à filosofia das luzes muitas concepções sobre a criança se modificam: a fragilidade e a inocência se libertam da referência ao pecado original, a natureza torna-se uma referência positiva. Os humanistas, e depois Locke, evidenciam consideração pela realidade da criança, respeito por ela e por sua liberdade, mas ainda se pretende o seu controle e as atividades espontâneas da criança não são consideradas. (BROUGÈRE, 1998, p. 62)

Com o movimento romântico ocorre uma oposição às concepções da filosofia das luzes, à visão científica do mundo, e um retorno ao obscuro, ao irracional, ao arcaico, ao primitivo. Nesse contexto, a infância é evocada positivamente e se dá uma ruptura em relação à visão anterior de criança e de jogo infantil. A criança passa a ser vista como representante da natureza e boa ao nascer; ligada ao primitivo, ao selvagem, ao popular, à verdade (ao primeiro, ao original), à intuição sensível, opondo-se a uma razão estéril. É relacionada ao poeta em virtude de seu acesso ao poético, à totalidade, à verdade. Sua inocência e fraqueza a preservam da realidade e da mentira. Por trás de uma aparente fraqueza, encontra-se um dinamismo interno, fator de desenvolvimento que encontra tudo em si mesmo. A criança não é vista como menor, mas como "mais"; não é mais um adulto em miniatura, mas em germinação (BROUGÈRE, 1998, p. 62)

A valorização da espontaneidade natural das crianças conduz à reavaliação da brincadeira, que passa a ser vista como comportamento por excelência da criança rica em potencialidades interiores. E essa idéia de comportamento verdadeiro e natural implica ser desprovido de razão e desvinculado do contexto social (WAJSKOP, 1995, p. 20).

Os vínculos entre brincadeira e educação, segundo a autora, ampliam-se também a partir de inúmeros fatores, como a valorização da criança no seio da família nuclear; as necessidades educacionais de seu controle e orientação; a entrada da mulher no mercado trabalho e de pedagogos humanistas e médicos iluministas preocupados com a moral, a saúde e o bem-comum, cujo alvo principal eram as crianças. 
Deve-se ressaltar também o papel dos primeiros pedagogos da educação préescolar, Fröebel (1782-1852), Montessori (1870-1909) e Decroly (1871-1932), responsáveis pela ruptura com a educação verbal e tradicionalista dessa época e pela introdução de uma educação sensorial/natural dos instintos infantis, sustentada na utilização de jogos e materiais didáticos (WAJSKOP, 1995, p. 21).

No final do século XIX nasce a psicologia da criança, que desenvolve um pensamento científico a partir da biologia e, acessoriamente, da antropologia. Essas novas teorias justificarão com argumentos parcialmente novos a relação entre jogo e desenvolvimento ou educação da criança.

Entre as teorias psicológicas do início do século XX , a corrente histórico-cultural e, mais especificamente, um de seus teóricos, L. S Vygotskii, rompe com a visão que concebe as brincadeiras como atividades naturais de satisfação de instintos infantis. Consideradas atividade psicológica de apropriação de instrumentos e de signos sociais, as brincadeiras "passam a ser compreendidas como resultado da experiência direta com os adultos, com associação de novos significados através da observação e da imitação espaço de interação social e de construção de conhecimentos pelas crianças" (PRADO, 1999, p. 2).

Vygotskii afirma a importância fundamental do papel da interação social no desenvolvimento do ser humano e procura explicitar, em suas teses, que o processo de desenvolvimento é socialmente constituído. Seu ponto de vista rompe com paradigmas anteriores sobre o desenvolvimento infantil ao afirmar que aquilo que é inato não é suficiente para produzir o indivíduo humano na ausência da ambiência social. As características constituidoras do indivíduo - os modos de pensar, agir e sentir, os valores, conhecimentos, etc. - dependem da interação do ser humano com o meio físico e social. Portanto, considera impossível conceber o desenvolvimento do sujeito como um processo previsível, linear ou gradual, pois esse processo está intimamente vinculado ao contexto sociocultural e se processa de forma dinâmica e dialética (REGO, 1998, p. 58).

Assim entende-se o desenvolvimento humano como um empreendimento conjunto e não individual, construído na e pela interação das crianças com outras pessoas, especialmente aquelas com as quais são mais envolvidas afetiva e efetivamente, e é fruto de experiências anteriores, que servem de base para novas construções. 
É através da interação com outras pessoas, adultos e crianças, que, desde o nascimento, o bebê vai construindo suas características: modos de agir, pensar, sentir e sua visão de mundo, seu conhecimento. Assim sendo, a idéia de interação ('inter-ação' ), ou seja, de ação partilhada envolvendo as ações de, no mínimo duas pessoas, é destacada (OLIVEIRA et al., 1994, p. 30).

O comportamento de uma criança muito pequena, conforme Vygotskii (1994, p.126), é determinado de maneira considerável - e o de um bebê de maneira absoluta pelas condições em que a atividade ocorre, isto é, os objetos ditam à criança o que ela tem que fazer: uma porta solicita que a abram e fechem e uma escada que a subam.

Segundo Vygotskii (1994, p.122), o brinquedo parece ter sido inventado quando as crianças começaram a experimentar desejos irrealizáveis, quando surgiram os desejos que não podem ser imediatamente satisfeitos ou esquecidos, e permanece ainda a característica do estágio precedente de uma tendência para a satisfação imediata desses desejos. A criança então, para resolver essa tensão, envolve-se num mundo ilusório e imaginário, onde os desejos não realizáveis podem ser realizados.

Segundo Vygotskii (1994, p. 127), ao brincar a criança aprende a atuar numa esfera cognitiva que depende de motivações internas, ou seja, a criança aprende "a agir numa esfera cognitiva, ao invés de uma esfera visual externa, dependendo das motivações e tendências internas, e não dos incentivos fornecidos pelos objetos externos."

No brinquedo, portanto, os objetos perdem sua força determinadora. "A criança vê um objeto, mas age de maneira diferente em relação àquilo que vê. Assim é alcançada uma condição em que a criança começa a agir independentemente daquilo que vê." E a ação, numa situação imaginária, ensina a criança a dirigir seu comportamento não somente pela percepção imediata dos objetos ou pela situação que a afeta de imediato, mas também pelo significado dessa situação (VYGOTSKII,1994, p.127).

Então, segundo Vygotskii (1994, p. 128), na idade pré-escolar ocorre, pela primeira vez, uma divergência entre os campos do significado e da visão. Ou seja, no brinquedo, o pensamento está separado dos objetos e a ação surge das idéias e não das coisas: um pedaço de madeira torna-se um boneco e um cabo de vassoura torna-se um cavalo. "A ação regida por regras começa a ser determinada por idéias e não pelos objetos." Essa inversão na relação criança/situação concreta/real é tamanha que seu significado não pode ser subestimado. É uma transformação que não acontece de uma só vez, porque é extremamente difícil para a criança separar o pensamento (o significado de uma palavra) dos objetos. O brinquedo fornece um estágio de transição 
nessa direção sempre que um objeto (um cabo de vassoura, por exemplo) torna-se um pivô dessa separação (entre o significado "cavalo" de um cavalo real). Nessas situações, a criança imagina, abstrai as características dos objetos reais.

Ao desempenharem papéis durante as brincadeiras, as crianças reproduzem com fidelidade aquilo que observam na realidade, atuando, portanto, além do comportamento habitual de sua idade. Essas situações, de acordo com Vygotskii (1994), criam uma zona de desenvolvimento proximal, na medida em que impulsionam conceitos e processos em desenvolvimento.

Mas é importante destacar que só quando adquirem a linguagem e passam a utilizar a representação simbólica é que as crianças têm condições de libertar seu funcionamento psicológico dos elementos presentes no momento atual.

A conquista da linguagem, que tanto expressa o pensamento da criança como atua como organizadora desse pensamento, segundo Vygotskii (1994), representa um marco no desenvolvimento do homem. Ao interagir e dialogar com crianças mais velhas e adultos, a criança aprende a usar a linguagem como instrumento de pensamento e de comunicação, o que lhe possibilita providenciar instrumentos auxiliares na solução de tarefas difíceis, que superam a ação impulsiva, planejar a solução para um problema antes de sua execução e controlar seu próprio comportamento.

\subsection{O Brincar como ação social}

Manuela Ferreira (2004, p. 82) é outra pesquisadora que problematiza a idealização do brincar.

[...] no Ocidente, desde a revolução romântica do século XVII, assistese à construção social de uma idealização do brincar que, repousando sobre o pensamento filosófico, instaurador de uma nova maneira de pensar a natureza, encontra posteriormente nos saberes da Biologia e da Psicologia do Desenvolvimento, na afirmação e expansão de um mercado de bens para a infância e nas políticas do Estado de protecção à infância e de bem-estar social os fundamentos legitimadores de uma definição sócio-psico-pedagógica da criança que faz do brincar o suporte essencial, positivo, espontâneo e natural do seu desenvolvimento (BROUGÈRE, 1995 apud FERREIRA, 2000).

Além disso, a autora aponta um outro aspecto relacionado à idealização do brincar. Ao distinguir-se a identidade social das crianças da dos adultos, a quem imputa-se a obrigação do trabalho, o brincar tornou-se "uma espécie de arquétipo da atividade das 
crianças, característica mais saliente do seu mundo de vida e no seu maior emblema", evidenciado no corolário: "brincar é o ofício da criança" (FERREIRA, 2004, p.82, grifos nossos).

Tradicionalmente, este oficio tem apresentado o brincar como algo a que as crianças aderem enquanto esperam para entrar na sociedade e em que são vistas como praticando ou simulando acções reais e relações entre as pessoas, numa espécie de cópia da realidade. É esta natureza de faz-de-conta que, construída socialmente como traço dominante das brincadeiras, as dissocia da realidade social imediata da qual fazem parte. Esta mesma natureza, tem levado à desconsideração das inúmeras relações entre o brincar e a realidade em que se insere $e$ que imediatamente o rodeia e, portanto, à sua infantilização. Brincar seria assim, sinônimo de socialização das crianças no mundo adulto e esta equivalente a preparação para a vida pela incorporação antecipada de papéis sociais. (FERREIRA, 2004, p.82, grifos nossos)

Outras perspectivas mais antropológicas, segundo a autora, ao discutir as relações de distinção ou conexão entre brincar, jogar e trabalhar que separam as crianças do mundo real e do mundo adulto ${ }^{5}$, fixaram o brincar em formas anacrônicas de brincadeiras, jogos, rimas, lengalengas, e remeteram a brincadeira "à idéia de cultura infantil como tradição, dando-lhe o tom de folclore e, aos olhos dos adultos um filão exótico a descobrir" (FERREIRA, 2004, p.82, grifos nossos).

Ferreira (2004, p. 83, grifos nossos) propõe então apreender o brincar para captar a ordem instituinte das crianças, considerando que estaria aí a possibilidade de "ultrapassar uma concepção assente na preparação para a vida adulta por uma outra que o valoriza no presente, como forma fluente de construção social dos seus mundos de crianças pela participação em actividades situadas no contexto social."

Diante do exposto, a autora propõe reconceitualizar o brincar, concebendo-o como ação social:

Reconceitualizar o brincar como ação social, ao subvencionar o brincar de faz de conta como um ato do mundo e a participação das crianças como um estatuto de estar neste mundo - ambas reveladores das suas interpretações acerca da realidade e das suas formas de, partilhando a sua visão do mundo, criarem realidades alternativas às dos adultos - , assume que o brincar não está separado do mundo real (FERREIRA, 2004, p.84).

Brincar, nessa perspectiva, é um dos meios de realizar e agir no mundo, não apenas para se preparar para ele, mas usando-o como recurso comunicativo, com o objetivo de

\footnotetext{
${ }^{5}$ Cf. Callois (1958); Huizinga (1954); Denzin, (1977); James (1993); Lopes (1998)
} 
participar na vida cotidiana pelas versões da realidade que são feitas na interação social, dando significado às ações. Então, brincar é parte integrante da vida social e é um processo interpretativo com uma textura complexa, onde fazer realidade requer negociações do significado, conduzidas pelo corpo e pela linguagem (FERREIRA, 2004, p.84).

Para Ferreira (2004, p.85), a valorização do brincar articula-se à necessidade de compreender as ligações do brincar de faz-de-conta com as relações sociais que prendem as crianças à vida real e também com os usos sociais que elas fazem do brincar no brincar:

Reivindica-se o brincar como uma parcela central das ações comuns que as crianças desenvolvem, sobretudo para se perceber como é que com "isso" elas constroem a sua cultura e se autoregulam como grupo social. Ou seja, como é que ao desenvolverem acções comuns, as crianças estão envolvidas e a participar como membros de um grupo e implicadas em processos de aprendizagem social e cultural pelos quais a sua cultura se realiza. (FERREIRA, 2004, p. 85)

\section{Considerações Finais}

O estudo da brincadeira nos cursos de formação de professores de educação infantil tem o propósito de contribuir para a compreensão de que essa é uma das ações mais importantes da vida das crianças. Além disso, procura-se evidenciar que nas instituições escolares e de educação infantil historicamente tem-se concebido as brincadeiras das crianças como manifestações naturais, como recreação, como meio de ensinoaprendizagem, considerando freqüentemente o jogo didático como seu sinônimo. Em virtude disso, secundariza-se e ofusca-se sua significação na vida das crianças.

Além da necessidade de reconceitualizar a brincadeira, como defende Ferreira (2004), aspectos como as interações, as diversas linguagens e a imaginação, que têm na infância uma estreita vinculação com a brincadeira e que assumem um papel fundamental em nossa constituição como seres humanos, precisam tornar-se efetivamente objetos de estudo e reflexão. 
Por fim é preciso dizer que um dos grandes objetivos desse trabalho no âmbito da formação de professores é refletir sobre algo que as crianças nos "dizem" insistentemente, de diversas formas, provavelmente porque se tenha muita dificuldade de ouvi-las e levá-las a sério: que as suas brincadeiras têm sentido em si mesmas e que são fundamentais em suas vidas!

\section{REFERÊNCIAS}

BATISTA, Rosa; CERISARA, Ana Beatriz; OLIVEIRA, Alessandra M. R. de \& RIVERO, Andréa S. 2002. Partilhando olhares sobre as crianças pequenas: reflexões sobre o estágio na educação infantil. In: $12^{\circ}$ Encontro Nacional de Prática de Ensino (ENDIPE), Curitiba. Conhecimento Local e Conhecimento Universal. CD Room. 2004.

BATISTA, Rosa. 1998. A rotina no dia-a-dia da creche: entre o proposto e o vivido. Florianópolis, SC. Dissertação (Mestrado em Educação) Universidade Federal de Santa Catarina.

BROUGÈRE, Gilles. Jogo e Educação. Porto Alegre:Artes Médicas. 1998.

BUFALO, Joseane M. P. Creche: lugar de criança, lugar de infância. Um estudo sobre as práticas educativas em um CEMEI de Campinas/SP. Dissertação de mestrado, FE-UNICAMP, 1997.

CERISARA, A. B. De como o Papai do Céu, o Coelhinho da Páscoa, os Anjos e o Papai Noel foram viver juntos no céu. In: KISHIMOTO, T. M. O brincar e suas teorias. São Paulo : Pioneira Thomson Learning, 2002. p. 123-138

COUTINHO, Ângela Scalabrin. 2002. As crianças no interior da creche: a educação e o cuidado nos momentos de sono, higiene e alimentação. Florianópolis, SC. Dissertação de Mestrado. Universidade Federal de Santa Catarina.

FERREIRA, Maria Manuela. Do avesso do brincar ou ... as relações entre pares, as rotinas da cultura infantil e a construção da(s) ordem(ens) social(ais) instituinte(s) das crianças no jardim de infância. In: SAMENTO, Manuel J.; CERISARA, Ana Beatriz (orgs.). Crianças e Miúdos: perspectivas sociopedagógicas da infância e educação. Porto: Asa editores, p. 55-104, 2004.

GOBBI, Márcia. 1997. Lápis vermelho é coisa de mulherzinha: desenho infantil, relações de gênero e educação infantil. Campinas, SP. Dissertação (Mestrado em Educação) Universidade Estadual de Campinas.

GUSMÃO, Neusa Maria M. de.1999. Linguagem, cultura e alteridade: imagens do outro. In: Cadernos de Pesquisa. n. 107, julho, p. 41-78. 
LARROSA, Jorge. 1998. O enigma da infância ou o que vai do possível ao verdadeiro. In: LARROSA, Jorge \& LARA, Nuria Péres de. (orgs.) Imagens do Outro. Petrópolis, RJ: Vozes, p. 67-86.

MACHADO, M. L. de A. Formação e valorização do profissional de educação infantil. In: II SIMPÓSIO NACIONAL DE EDUCAÇÃO INFANTIL, 1996, Brasília. (mimeograf.)

OLIVEIRA, Alessandra Mara Rotta de. 2001. Do outro lado: a infância sob o olhar de crianças no interior da creche. Florianópolis, SC. Dissertação de Mestrado. Universidade Federal de Santa Catarina.

PRADO, Patrícia D. 1998. Educação e cultura infantil em creche: um estudo sobre as brincadeiras de crianças pequenininhas em um CEMEI de Campinas, SP.Dissertação de Mestrado. Universidade Estadual de Campinas.

REGO, Teresa C. Vigotsky: uma perspectiva histórico-cultural da educação. Petrópolis: Vozes, 1998.

SOARES, Natália F. Direitos da criança: utopia ou realidade? In: PINTO, Manuel; SARMENTO, Manuel J. (coord.) As crianças: contextos e identidades. Braga, Portugal: Centro de Estudos da Criança, p.75-112, 1997.

SOUZA, Solange Jobim \& PEREIRA, Rita Marisa R. 1998. Infância, conhecimento e contemporaneidade. In: KRAMER, Sonia \& LEITE, Maria Isabel (org.) Infância e produção cultural. Campinas, SP: Papirus, p. 25-42.

VYGOSTKY, L. S. A formação social da mente: o desenvolvimento dos processos psicológicos superiores. São Paulo: Martins Fontes, 1994. 